\title{
Social Machines: How recent technological advances have aided financialisation
}

\author{
Tiejun $\mathrm{Ma}^{1}$, Frank McGroarty ${ }^{2}$
}

\begin{abstract}
In recent years, financial markets have been fundamentally transformed by innovations in information technology, in particular with regard to the web, social networks, high-speed computer networks and mobile technologies. We borrow the concept of Social Machines from Web Science as a single concept that captures the essence of all these recent technological changes to argue that the emergence of these Social Machines has aided the transformation of financial markets and society. This study explores the formation of these Social Machines with three sample disruptive technologies - automated/high-frequency trading, social network analytics, and smart mobile technology. Through critical reflective analysis of these three case studies, we assess the impact of information technology innovation on financialisation. We adopt three case studies - automated trading; market information extraction using social media technologies; and information diffusion and trader decision-making with mobile technology on financial and real sector changes - which demonstrate the increasing trend of transaction velocity, speculative trading, increased complex information network, accelerated inequality and leverage. Our findings demonstrate that technologically enabled financial Social Machines harness crowd wisdom, engage disparate individual traders to produce more accurate price estimations, and have enhanced decision-making capability. However, these same changes can also have a simultaneously detrimental effect on financial and real sectors, in some situations exacerbating underlying distortions, such as misinformation due to complex information networks, speculative trading behaviour, and higher volatility with transaction velocity. Overall, we conclude that these innovations have transformed the fundamental nature of key aspects of the finance industry and society as a whole.
\end{abstract}

Keywords - Financialisation, Social Machines, Information Technology, High Frequency Trading, Trader Behaviour, Sustainability

\section{INTRODUCTION}

The financial system has undergone tremendous changes over the last decades with increasingly complex information networks (e.g., social network), increased transaction speed (e.g., high frequency trading), and increased speculative behaviour with derivative financial instruments. It is a complex multi-faceted system embedded in interpersonal networks, geographical territories and physical spaces; in social institutions, political structures and cultural forms (Hertz, 1998; Muniesa, 2014). For example, Stoll (2006) speculated to what extent much trading would be automated by technology; and now, there is almost a complete transformation from manual to automated processes. These algorithms have completely revolutionised the world and have restructured all aspects of the financial sector, with an inevitable impact on our societies. This has placed growing importance on the misalignments between human intentions and automated actions carried out by computer programs (Lenglet, 2011), while technologies may also exhibit biases that reflect the social and cultural contexts in which they were developed (Feenberg, 2005). Consequently, it is important to understand how stakeholders and organisations engaged in the global financial system are impacted by these complex multi-faceted technologies. To achieve such a goal, we borrow the concept of Social Machines from Web Science as a single idea that captures the essence of all these recent technological changes. We argue that the emergence of these Social Machines has aided global financialisation - a concept defined as "the increasing dominance of financial actors, markets, practices, measurements and narratives at various scales, resulting in a structural transformation of economies, firms, states and household" (Aalbers, 2015).

Shadbolt et al. (2013) argue that in web systems with their information-sharing nature and social aspects such as Wikipedia, Twitter and Facebook, users are part of a communitybased social computation. Such a system adds value implicitly or explicitly as individuals contribute to the overall knowledge system. This structure also applies to financial markets where users

\footnotetext{
${ }^{1}$ Centre for Risk Research, Southampton Business School, University of Southampton

${ }^{2}$ Centre for Computational Finance and Business Analytics, Southampton Business School, University of Southampton
} 
are empowered within the system. We contend that the rapid development of the web and mobile technology with billions of users worldwide allows us to envisage financial markets as Social Machines. This term was first coined by Berners-Lee and Fischetti (1999) to mean "processes in which the people do the creative work and the machine does the administration". Smart et al. (2014) characterise Social Machines as having four important characteristics: (i) they are socio-technical systems involving human and technology participation; (ii) they are web-based systems; (iii) they consist of multiple human individuals, and (iv) they are the physical systems that realise the combined contributions of multiple individuals and processes. Financial systems are similarly the result of human and computer interactions. Over the past few decades, these systems have migrated from the trading floor to electronic, web-based venues. Hence, we invoke the financial Social Machine idea to conceptualise the physical form of these processes as fragmented traders collectively compete not only to erode asset mispricing but also to increase transaction velocity and improve financial market integration.

As Grossman and Stiglitz (1980) point out, the economic incentive to participate means that people actively engage in identifying and arbitraging misaligned prices within the system. The theory of Social Machines provides a holistic framework within which to capture an ensemble view of financial systems as the boundary between human and machine processes has become increasing blurred. This is evidenced in the flash and hack crashes respectively, where the interplay between and balance of human and machine parts has been skewed to the point where machines are dominant due to their high-speed information-processing power; yet they continue to represent human speculative intent. Indeed, the sheer volume of available in today's globalised and technology-driven world necessitates a human-machine symbiosis that transcends fully automatable solutions. Information from a myriad of computers and sensors, together with human input, constitutes a "cyberinfrastructure" (Ekbia et al., 2015) which enables decision makers to make better-informed decisions.

To date, only limited studies have focused on how this financial cyberinfrastructure information system functions. Bannister and Remenyi (2000) argue a need for better understanding of how, generally, information technology is incorporated in the reality of decision making, while Brogaard et al. (2010) contend that automated trading unequivocally improves stability as agents trade in the direction of permanent price movements. However, faster information due to algorithmic trading has also been heavily attacked as the alleged cause of the May 6, 2010 Flash Crash, (Johnson et al., 2013). This crash was caused when US stock market indices, stock-index futures, options and exchange-traded funds experienced a precipitous but fleeting decline in prices (Vuorenmaa, 2012), driven by a sudden drop of more than five per cent followed by a swift and comparably sharp rebound of similar magnitude. Therefore, to shed light on the inherent ambi- guities that surround this multi-faceted complex system, we employ a qualitative research approach to achieve a more in-depth understanding of the role of information technology in the transition towards an entirely different capitalist typology (Cloke, 2013) by means of a qualitative research approach using three distinct case studies. These involves three case studies including automated trading, social network, and mobile technology themes, where we reflect the transaction velocity, increasingly complex information networks, speculative trading, accelerating inequality and leverage aspects of financial systems. These features, in turn, are shaped by automated technologies, market information formation via social networks, and information diffusion/trading decision-making through mobile technologies.

The first two case studies focus primarily on the institutional traders' side and its impact on financial/real sectors. For example, Case study 1 looks at automated machine-based trading where autonomous software agents - i.e. "trading bots", acting for and on behalf of their human owner/creators - aim to accumulate profit from trading activities. We discuss how this study may improve our understanding of the dynamics of the financial system and how high frequency trading may accelerate the impact of these dynamics not only within the finance sector but also on society in general. The second case study focuses primarily on social network information and how new techniques such as sentiment analysis can improve decision making from crowd-based opinion through complex information networks. Our final case study analyses how mobile technology allows information to propagate across market participants, thereby influencing their speculative behaviour and widen the social divide. For example, mobile phones facilitate easier and more efficient access to information, which in turn leads to faster response times and superior decisions for adopters of such technology. Better trading decisions lead to increased profits from speculation, thereby widening the income inequality gap.

Our paper is a critical narrative of how these new technological innovations enabled the emergence of financial Social Machines and how these form a complex adaptive system. Understanding these changes to the financial system and their implications is essential for an understanding of the phenomenon of financialisation.

\section{Literature REVIEW ANd RESEARCH MOTIVATION}

The tremendous expansion of the financial sector, with the sophistication of financial products and velocity at which financial transactions take place has created unprecedented complexity (Lagoarde-Segot, 2016). Consequently, scholars from a range of disciplines have tried to capture this shift from industrial to financial capitalism and assess its impact on the global economy and society (Van der Zwan, 2014). What unites these literary works is a view that finance has moved beyond its traditional role as a 
provider of capital for the productive economy. It becomes an autonomous global financial systems where the dynamics of the industrial economy and the inner workings of democratic society have been transformed (Lin and Tomaskovic-Devey, 2013; Lagoarde-Segot, 2015; Lagoarde-Segot, 2016; Lagoarde-Segot and Paranque, 2016).

Due in part to the huge increase of support for financialisation within the social sciences, what stems from the ability to provide an interdisciplinary convergence point that embraces several nested levels, such as economic systems, geography, technology, macroeconomic policies, microeconomic behaviour, social narratives and so forth (Lagoarde-Segot, 2016). Therefore, due to this complexity, employing traditional hypothetico-deductive models or empirical proxies used by financial economists may not always be the most appropriate means of investigation. This is because the environment has highly inter-connected and dynamic elements with multiple feedback loops, oscillations and side effects (Arndt, 2006), which makes behaviour much more difficult to anticipate within an environment, which is counter-intuitive, non-linear, and irreversible (Sterman, 2000). This then raises the question of whether the traditional methods applied by financial economists are the right tools for the job, in today's multi-faceted global financial systems.

In addition, the dynamics of competition and natural selection shape market ecology and change the population of rational and irrational market participants (market evolution). With the ultimate survival aim of traders and frequently turbulent market conditions (e.g., financial crisis), both institutional and individual traders are seeking technology advantages. This would help traders and financial institutions to achieve competitive advantage for information efficiency with automated high-frequency trading (Hendershott et al., 2011), news analytics (Schumaker and Chen, 2008; Foucault et al., 2015), and social network analysis (Constantiou and Kallinikos, 2015) for institutional traders. The availability of Smart Phones with ubiquitous connections to the mobile internet also allows individuals to access market information and make decisions instantly. Similarly, information technologies, particularly the forming of financial Social Machines, may play important roles in the financial industry formation process: the same way that significant changes in environmental conditions do. Technology improvement can force rapid evolutionary changes in populations of market participants (Cameron et al., 2013) and may result in turbulent market conditions. It is likely that volatile market conditions could foster the evolutionary forces underpinning the efficiency of price and the population of market participants, forcing out the most unprofitable and technology-disadvantaged traders. . As a result, financial crises and information technology enhancement should accelerate the evolution process and the shakeout of "weak" market participants (e.g., technology-disadvanced institutional/individual traders).
Consequently, an important question is how finance Social Machines, such as the adoption of agent-based high-frequency trading, social network/sentiment analysis and smart mobile devices as an ecological system impact on the financial systems, particularly on speculative behaviour, transaction velocity and increased inequality. For instance, Barber and Odean (2001) contend that certain groups of people are generally overconfident with speculative trading behaviour. Prospect Theory (Tversky and Kahneman, 1974) provides a widely accepted framework to describe an individual's behaviour and biases. Where finance institutions are based more on automated trading with technologybased quantitative trading strategy, can such biases be prevented with the adoption of enhanced technology, or, actually, are automated trading models only as smart/rational as their designers? Will trading speculation, leverage, and wealth inequality actually be further amplified by the new technology (e.g., high-frequency trading based on biased trading strategy)?

High-Frequency Trading (HFT) and Algorithmic Trading (AT) have become dominant strategies in financial markets. Reporting on a sample of 120 countries, Jain (2004) shows that the shift to electronic trading systems has enhanced liquidity and improved price discovery as more information is incorporated into the stock markets, making markets more efficient. While automation and high-frequency trading improve market ecology, there are risks to fully automated systems as evidenced by crashes. Flash crashes occur when stock indices fall and rebound in relatively short periods, which, as stated, may be beyond human perception. Clemons et al. (2013, p.375) states that "the underlying cause of the crisis was human error and hubris in the form of overconfidence and speculative excess". As trading becomes increasingly automated, research has shown that, on average, AT can increase market efficiency and price discovery in day-to-day trading but that, at other times and in extreme circumstances, machines can exacerbate underlying problems. In addition to crashes, strategies such as HFT may emphasise market characteristics. As Brandt and Neumann (2015) point out, the trading surrounding the crash was driven by endogenous effects such as herding instead of genuine responses to new information. Further, they postulate that certain strategies (such as HFT) that may have contributed to the crash may also eventually benefit from such events so there may be a reluctance to change what could ultimately be a winning strategy. Also McGroarty et al. (2009) show that markets which lack market-makers will be more susceptible to price changes and specifically errors when there is an imbalance between buyers and sellers so that they become more volatile particularly at high frequency. Since HFT trading continues to dominate modern markets, crashes may become more common and the imbalances they cause may lead to severe economic problems from which some traders may in fact profit.

Ultimately, technology has revolutionised modern markets and brought about an increasing focus on speed as information is incorporated into prices more rapidly. However, at the 
same time, this speed will heighten underlying market imbalances. Granados et al. (2006) aptly summarise the impact of trading automation on market characteristics (see Table 1):

Table 1.Market Design Dimensions and Impact of IT

\begin{tabular}{|c|c|c|}
\hline $\begin{array}{l}\text { MARKET DE- } \\
\text { SIGN DIMEN- } \\
\text { SIONS }\end{array}$ & DESCRIPTION & IMPACT \\
\hline \multicolumn{3}{|c|}{ Informational Features } \\
\hline $\begin{array}{l}\text { Market Trans- } \\
\text { parency }\end{array}$ & $\begin{array}{l}\text { Availability and } \\
\text { accessibility }\end{array}$ & $\begin{array}{l}\text { Increases po- } \\
\text { tential for com- } \\
\text { plete, accurate, } \\
\text { and unbiased }\end{array}$ \\
\hline Price Discovery & $\begin{array}{l}\text { Process by } \\
\text { which market } \\
\text { prices are estab- } \\
\text { lished }\end{array}$ & $\begin{array}{l}\text { Enables inno- } \\
\text { vative and dy- } \\
\text { namic mecha- } \\
\text { nisms }\end{array}$ \\
\hline $\begin{array}{l}\text { Trading Proto- } \\
\text { cols }\end{array}$ & $\begin{array}{l}\text { Transaction pro- } \\
\text { cess and rules }\end{array}$ & $\begin{array}{l}\text { Increases flex- } \\
\text { ibility to set trad- } \\
\text { ing rules }\end{array}$ \\
\hline \multicolumn{3}{|c|}{ Degree of Automation } \\
\hline Efficiency & $\begin{array}{l}\text { Speed and cost } \\
\text { of transactions }\end{array}$ & $\begin{array}{l}\text { Increases effi- } \\
\text { ciency }\end{array}$ \\
\hline Reach & $\begin{array}{c}\text { Frequency of } \\
\text { transactions and } \\
\text { geographical reach }\end{array}$ & $\begin{array}{c}\text { Increases reach } \\
\text { potential }\end{array}$ \\
\hline $\begin{array}{l}\text { Reliance on In- } \\
\text { termediaries }\end{array}$ & $\begin{array}{l}\text { Degree of inter- } \\
\text { mediation }\end{array}$ & $\begin{array}{l}\text { Enables elec- } \\
\text { tronic intermedia- } \\
\text { tion and direct } \\
\text { trading }\end{array}$ \\
\hline
\end{tabular}

In addition to AT/HFT, social media has revolutionised how financial markets operate (Aral et al., 2013) and is a rich source of information that traders are increasingly using for competitive advantage. Research has shown that there are useful unstructured data on the web that can be harvested to predict stock prices. Chen et al. (2014) for example show that investor opinions on crowd-sourced websites were useful for predicting stock prices and produced economically significant returns. Sprenger et al. (2014) find that the information contained in tweets ${ }^{3}$ was positively associated with stock returns and the volume of tweets was associated with volume of trade, and. conclude that negative news contained in tweets had a stronger impact on stock prices than positive news had. These examples highlight how valuable information related to stock prices is contained in information posted by users online, and that this information can be readily applied to predict market prices. Social media represents the fusion of the social and technical domains where social activities are produced in technical material that is becoming ingrained in business strategy (Constantiou and Kallinikos, 2015).

While social media offers potential benefits to traders to predict market activity, there are nevertheless a number of problems. First, social media is unstructured, noisy and high in volume so that the process of finding useful information requires extensive pre-processing, cleaning and analysis of the data. Second, as discussed above, technology helps to almost instantaneously incorporate information into the market, which can prove to be hazardous when the content is malicious. In April 2013, the Twitter account of Associated Press was hacked and the hackers fraudulently posted a tweet stating "Breaking: Two Explosions in the White House and Barack Obama is injured" which reverberated around Twitter. At the same time the Dow Jones Industrial average dropped 143.5 points and the Standard \& Poor's 500 index fell by $\$ 136.5$ billion (Karppi and Crawford, 2016, p. 74). In the space of five minutes, the tweet was verified as fraudulent and the markets returned to pre-crash levels. The event, labelled the 'hack crash', serves to show the relationship between social media and financial markets: the interplay between human social activities on Twitter and machine-automated processes that monitor social data and trade upon gleaned information that causes market prices to change.

Moreover, the competitive pressures of modern financial markets have built a culture of speed. Indeed the time difference between humans and computers reading articles offers an advantage to those who are able to discern accurate price signals fastest. Leinweber and Sisk (2011) highlight such a strategy as they use machine-reading services to read and process news articles into price signals that can be used to generate profitable returns. More recent research using financial news services, such as those from Thomson Reuters, have found that market liquidity increases around the release of positive and neutral news but liquidity actually decreases around negative news (Riordan et al., 2013). Similarly, Thomson Reuters' sentiment signals are useful for predicting market returns, and Uhl (2014) finds that negative price sentiment signals have a stronger effect than positive news; they report a $34 \%$ profitable return using a strategy that takes advantage of this. In a highly automated market, analysis exists on a spectrum that ranges from machine to machine (HFT) activities to human-human activities monitored by machines. Financial traders are increasingly incorporating information from decentralised sources to make better-informed trades ahead of their competitors.

\footnotetext{
${ }^{3}$ www.twitter.com
} 
In summary, innovative Internet-related technology (such as social networks, mobile Internet) has accelerated since the inception of the internet and, "by analogy, firms with competitive advantages in those areas will need to move faster to capture those opportunities". Drnevich and Croson (2013) show that technology innovation can be a source of competitive advantage and profitability. Particularly for the finance industry, embedding technology in trading operations and making full use of new information in real time is the key to probing misprices and discovering investment opportunities. Recent studies examining the employment of web-based information to aid trading decision-making have shown the impact of new technology aggregation on the information environment (Xu and Zhang 2013). Such findings support the forming of Social Machines for financial markets. The emerging of such Social Machines allows us to observe the complex impact of information technology on financial markets at individual, market and societal levels (Chang et al., 2014). However, despite the fact that Social Machinery-based information technology has been transforming financial markets for almost a decade, little research has shown the extent to which Social Machinery affects financial markets (Zhang and Zhang, 2015). Therefore, despite the evolution of advanced information technology to push the boundary of trading speed and the forming of Social Machines on improving trading decisions, we still lack a fundamental understanding of when market conditions may be exacerbated by technology such as during flash crashes when machines may be overtly dominant in the human-machine agency. Technology such as AT and social media can accelerate the global financialisation process. However, the culture of speed also performs to the detriment of the entire financial system when there are extreme circumstances, and there is the need for further market efficiency and price remain largely unexplored, with current observations and theories relatively underdeveloped and somewhat broad. We choose an inductive (theory-building) approach as opposed to a deductive (theory-testing) one because it seemed inappropriate to confine the theoretical scope of the domain to a largely ill-defined subject that is still undergoing many dynamic and evolutionary changes. Considering this, we expect our qualitative approach to provide a holistic understanding of this domain where we combine methods, data sources, theory and investigators (Denzin, 1978) from a range of literature, including our own. This is to shed light on the inherent complexities and ambiguities that currently exist within this field.

To fulfil our research objective we thus adopt a qualitative case study approach; this is an "empirical enquiry" that investigates a contemporary phenomenon within its real-life context, particularly when the boundaries between phenomenon and context are not evident; and it relies on multiple sources of evidence (Yin, 1994). It is the most widely used qualitative research method in information systems research (Orlikowski and Baroudi, 1991) and is well suited to understanding the interactions between information technology-related innovations and organisational contexts (Darke et al., 1998). For example, Gozman et al. (2015) conducted a qualitative case study to discuss how global financial institutions are using big data analytics within their compliance operations. The case studies illustrated how technologies are implicated in multijurisdictional challenges and regulatory conflicts at each end of the operational risk spectrum. Similarly, Gozman and Currie (2014) explore to what extent the role of Investment Management Systems (IMS) enables the alteration of previously embedded practices. The authors analysed eight global financial organisations that have all used IMS. They found

\begin{tabular}{llll}
\hline & Description & Trader & Case Study Example \\
\hline Case Study 1 & $\begin{array}{l}\text { Automated Agent-based Trading } \\
\text { and High Frequency Trading }\end{array}$ & Institutional & $\begin{array}{l}\text { Alsayed and McGroarty, } \\
2012\end{array}$ \\
Case Study 2 & $\begin{array}{l}\text { Social Machine Information Diffu- } \\
\text { sion and Sentiment Analysis }\end{array}$ & Institutional & Gaskell et al., 2014 \\
Case Study 3 & $\begin{array}{l}\text { Mobile Internet, Institutional and In- Individual } \\
\text { dividual Trading }\end{array}$ & Moreno Paredes et al., 2014 \\
\hline
\end{tabular}

Table 2 Breakdown of Case study research

investigation to understand what safeguards must be in place to prevent machines from operating ungoverned in what is essentially a human-machine financially orchestrated symbiosis.

\section{METHODOLOGY}

How advances in web technology, social networks, highspeed computer networks and mobile technologies have affected that the institutionalisation of technology-induced compliant behaviour is still largely uncertain.

As emphasised by the examples, case study research is a useful means for studying information systems development, implementation and usage in the field (Darke, 1998). It has been used to achieve various research aims: to provide descriptions of phenomena, and to develop and test theory, and has often been associated with description and theory development, where it is used to facilitate exploration of areas where existing knowledge 
is limited (Cavaye, 1996). This exploratory approach, therefore, aims to complement incremental theory-building (Eisenhardt, 1989), which seems best suited to this domain. This is because it has more 'how' and 'why' questions that need to be reviewed; for example, in the context of price discovery and market efficiency evolution, due to the limited amount of research, the extent to which price discovery is affected by the integration of these technologies continues to be contested. Therefore, we believe it is the most appropriate methodology for our study. Considering this, we broke the domain up into three case studies - each one providing a unique angle for looking at price discovery and market efficiency evolution (see Table 2 for details).

The first two case studies focus primarily on the perspectives of the institutional traders and the market. For example, Case study 1 looks at automated machine-based trading where robots form the foundation of trading machines within the market. Discussion continues over how that may improve the price discovery process and how high-frequency trading may accelerate the speed of price discovery for institutional traders. The second case study focuses primarily on Social Machines, concerning how they offer new techniques such as sentiment and frequency analysis to extract crowd thinking about market price. The final case study analyses how technology influences an individual's trading behaviour; for example, how new technologies such as mobiles enable easier and more efficient accessibility to market information that, in turn, enables increased reaction times to enhance the price discovery process.

Overall, our case studies provide a critical narrative of how social platforms are impacting the efficiency of markets in regards to the internet, price discovery and formation. The next section presents our analysis and discussion of our research findings.

\section{Case Study 1: Financial InTEgration AND TransaCtion Velocity: AUTOMATED AND High FREQUENCY TRADING}

Automated trading (AT) technologies have revolutionised how financial markets are traded with pre-programmed rules to make automatic trading decisions. They have profound implications for the global financialisation and particularly for financial integration. Indeed, the electronic nature of the transactions and the availability of up-to-date order-book data make autonomous stock-trading applications a promising alternative to immediate human involvement (Sherstov and Stone, 2005). Jain (2004) highlights the main advantage of automated trading as that it usually has lower operating and order-processing costs. We use the work by Alsayed and McGroarty (2012) as an exemplar case study. The authors analysed Arbitrage and the Law of One Price in the market for American depository receipts to assess the market mechanism by which the Law of One Price is enforced through automated pairs trading based on matching a long position with a short one in a pair of mispriced securities, then liquidating that position upon convergence. This approach showed how such an arbitrage strategy forms the main price-correcting mechanism whereby arbitrage can maintain stock-ADR parity. This aim was achieved using 131 quote price observations, covering a sample of 25 firms in the UK that trade as ADRs on US exchanges. The authors found the risk associated with Pair Trading was very low, with returns of $1.45 \%$ in excess of the risk-free rate.

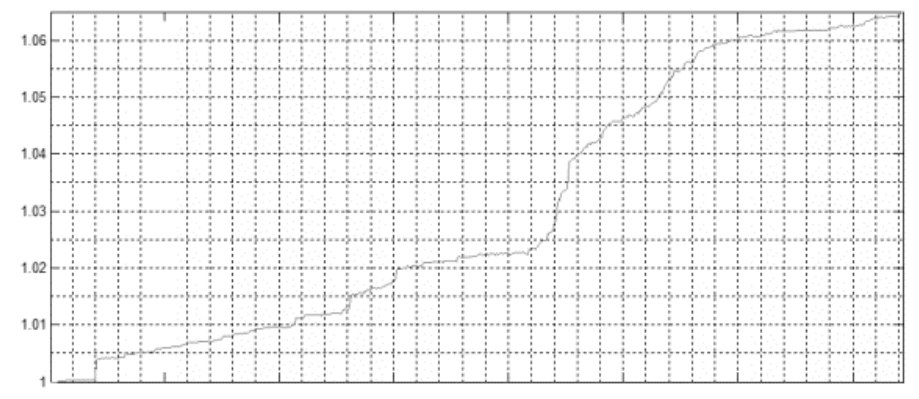

Fig 1. Cumulative Portfolio Wealth shows the cumulative daily wealth at the overall portfolio level, assuring an initial wealth Wo - $\$ 100$ on the vertical axis. The horizontal axis denotes the number of trading days.

Figure 1 highlights the cumulative wealth at the portfolio level (averaged across all the firms in the analysis); even at the daily level, there appears to be low volatility. This highlights the reduced risk from individual stock-ADR pairs across the exhaustive sample. Additionally, the authors identified that exploitable opportunities appeared throughout the interval period of the UK and US markets, although these were at random, as shown in Figure 2 . The dynamics of mispricing are shown to be highly meanreverting, exhibit minimal volatility and have short half-lives. The researchers found the main disincentive to stock-ADR arbitrage stems from uncertainty about the duration of the pairs trade. For example, for each additional cent demanded by arbitrageurs in per-share profit, the expected trade duration more than doubles, and the standard deviation of trade duration increases by $20 \%$. Finally, arbitrageurs who set their trade entry bounds higher will experience less duration uncertainty but will observe fewer trading opportunities. The authors conclude that the results show stock-ADR arbitrage is characterised by a high incidence of small, short-lived, exploitable mispricing, where arbitrage is an important element in enforcing stock-ADR parity, where pricing anomalies incentive arbitrageurs to restore price efficiency. Such a result resonates well with Hendershott and Moulton's (2011) findings that AT improves liquidity and contributes to velocity of price convergence to its true value as information is impounded into the pricing process much faster. This accelerated transaction velocity also demonstrates the increasing trend of financial integration of geo-political context with an unprecedented expansion 
of information technologies, and represents the emerging challenge of the need for proper trading regulations to balance both market liquidity and stability (Lagoarde-Segot, 2015). Lenglet (2011) asserts that AT has deeply restructured all aspects of the financial sector. There is a need to examine financial sectors with interdisciplinary dialogue to improve our understanding of the relationship between asset trading in the globalised digital market and the broader socio-political context (Cloke, 2013).

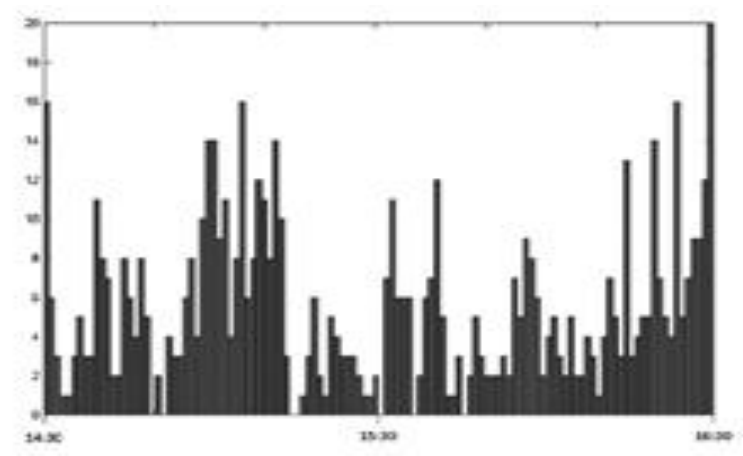

Fig 2.

Incidence of mispricings. Total number of arbitrage positions initiated across each 1-min contemporaneous interval of the trading day. The horizontal axis shows the GMT interval during which both the US and the UK exchange trade.

For example, automated trading machines accelerate the speculative behaviour of the market such as agent-based trading systems. They are a type of computational model that simulates the actions and interactions of autonomous agents, where -through a collection of decision-making entities - each assesses its own situation and makes a decision based on a set of predetermined rules. Consequently, they can yield powerful insights into market behaviour based on algorithms programmed into the model. Farmer (2001) created simple agents and assigned each one a variety of different trading strategies, with a learning algorithm to identify and exploit mispricing. As demonstrated by Figure 3, gradually the agents started to make the mispricing oscillation decrease. However, as the market continued towards complete efficiency, the agents themselves became the noise in the market; and at Time = 5000 , prices went instable as the traders continually tried to learn from each other's speculation. Such a result also demonstrates the problematic limitation that AT cannot understand the fabrication of the market financialisation process (such as understanding consumer confidence or sectarian conflicts or shareholder's value, etc.) and can only assume the discovery of price.

Furthermore, High-Frequency trading (HFT) has greatly accelerated transaction velocity. These are automated algorithms that capitalise on very short-lived information gleaned from publically available data. This is achieved using sophisticated quantitative techniques beyond human capacity with thousands of trades executed at nanosecond speed (Johnson et al., 2013, Chaboud et al., 2014). This result is in line with Hendershott and Moulton's (2011) finding that changes in market structure increase liquidity due to increased speed (Riordan and

Storkenmaier, 2012). It also raised the cost of immediacy, further accelerating the financial integration and speculative nature of the market participants. Hasbrouck and Saar (2013) compare the ever-increasing rate of trading speeds to an arms race as the fastest and most accurate traders are more likely to profit. The refined focus on speed of trading has improved the rate of information flow through complex information networks and thus facilitates price-related information by trading in the same direction of permanent price changes and opposite to pricing errors (Brogaard et al., 2014). However, such a technology also increases the income inequality as a societal concern and threat to security on a global scale (World Economic Forum, 2015). It also raises the question of whether high-speed transaction could actually raise the shareholder's value and improve society's wealth. However, it may actually amplify the speculative behaviour in the market, which poses challenges for more effective financial regulations (Lagoarde-Segot and Paranque, 2016).

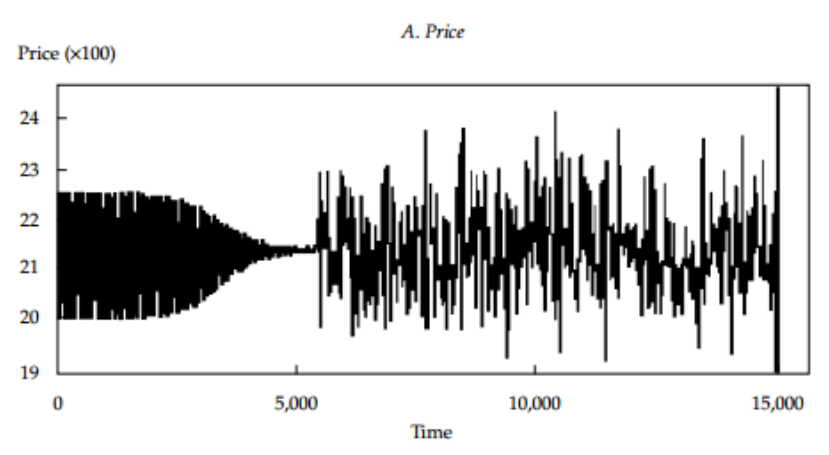

Fig 3.

Illustration of price fluctuation

Despite the fact that automated trading is able to increase market information flow, critics argue that it raises many regulation challenges regarding the role of human traders, trading machines, financial institutions and their socio-technical interaction, dynamism, and organisational structures as part of the critical theory of this technology (Feenberg, 2005). For example, if everyone operates in his or her own self-interest this can be collectively devastating to the dynamic financial system as a whole due to increased speculative behaviour and worsen income inequities for those technology-disadvanced traders (e.g., 'food for predators' according to the adaptive market hypothesis proposed by Lo, (2005)). Therefore, it raises moral concerns to align societal expectations with ethical business practices regarding the correct codes of conduct, where this is not necessarily just to maximise profits but also to ensure the stability of the system on which the traders are dependent (Lenglet, 2011). Similarly, coding mis- 
takes may also be exacerbated which in turn leads to higher market volatility and results in social turbulence. A case in point is critics arguing that HFT has been responsible for flash crashes (Kirilenko et al., 2011). Perhaps, the most famous crash was the May 6, 2010 Flash Crash where the United States stock market indices, stock-index futures, options and exchange-traded funds experienced a sudden and unprecedented increase in volatility (Vuorenmaa, 2012). Such events can have huge impacts when markets fluctuate to such an extent ; for example, the flash crash in May 2010 saw the E-Mini index fall by 55\% ( $\$ 3.35$ billion) and the SPY fall by $20 \%$ (\$55 million) (Commodities and Future Trading Commission (CFTC), 2010). The crash occurred around the time a large trader initiated a program to sell 75,000 E-Mini contracts (approximately $\$ 4.1$ billion value) in a short time frame (CFTC, 2010). While many theories on what caused the crash exist, according to Zigrand et al. (2011) this collapse had a knockon effect whereby it eroded confidence in markets for a considerable time afterwards. Although Kirinlinko et al. (2011) found that HFT firms were not the cause of the crash, they did however find that their aggressive trading in the direction of price changes exacerbated volatility, thereby creating a downward spiral affect. This is supported by the trading response of CFTC-SEC; although it did not place the blame on HFT firms, this still led to a sudden selling pressure, which added to volatility.

It is important to recognise that HFT decisions are made by automated agents faster than humans can respond. We are placing increasing power in the hands of software programs and machines. This will only be exacerbated as traders race to attain competitive advantage through speedier information, which will raise many more societal questions that will need answers. For example, 'time is risk', so reducing this time reduces the risk to the speculator. This refined focus on speed of trading has improved the rate of information flow and changed the geo-political space (and will continue to do so). With integration of inter-connectivity through the fibre-optically connected world of online digital media and communication, HFT has enabled financial actors such as hedge funds and private equity firms among others to front-run their trades and to take advantage of price gaps and arbitrage opportunities across a globally interconnected financial market. Hence, the geo-political space has changed as traders gain incremental speed and knowledge advantages through bilateral agreements with stock exchanges so that they can reside as physically close as possible (Garvey and $\mathrm{Wu}, 2010$ ). This raises many social problems such as creating an unfair advantage for the individuals who can embrace this technology as they have the necessary capital to do so. According to Duhigg (2009), this can create unprecedented volatility where we are moving toward a two-tiered marketplace of the high frequency arbitrage firms, and everyone else (Duhigg, 2009). This trading frequency revolution and the flash crash event highlighted a critical research question raised by Lagoarde-Segot, (2016): “Are 20th century fi- nance concepts and management principles still valid in the context of geopolitical finance, asset concentration, complex information networks, and sustainability crisis?"

In summary, automated trading has revolutionised modern markets and brought about an increasing focus on speed as information is incorporated into prices more rapidly. When HFTs are active, they help expedite market efficiency, increased finance integration, and speculation. The increased digitalisation and transaction velocity of trading has significantly increased the complexity of global financial products, thus leading to a new opaque and complex environment (Cloke, 2013; Lagoarde-Segot, 2016). In other words, financial integration has coincided with an unprecedented expansion of information technologies.

\section{CASE STUdY 2: COMPLEX FINANCIAL INFORMATION NETWORK: SOCIAL NETWORK INFORMATION DIFFUSION AND SENTIMENT ANALYSIS}

Finance information flows through complex information networks, such as rating agencies, banks and financial institutions, and prices are traditionally described as 'discovered' by exchanging information through such complex networks. However, a broader financialisation view is that prices are the product of an extended and mutually beneficial collaboration between various actors within complex information networks, and are fabricated and embedded within social, cultural, economic and technological contexts (Boussard, 2016). Within such a process, internet technology has played an important role due to its capability of sharing/collecting 'wisdom-of-the-crowd' information from social networks. We can refer to such technologies as Social Machines, a term used to describe technology-enabled social systems seen as computational entities governed by both computational and social processes (SOCIAM, 2014). In other words, these are processes in which users (e.g., actors within a financial network) do the creative work and the machines do the administrative part (BernersLee, 1999). This allows financial systems to tap into the collective intelligence offered by the Web environment, which contains not only the market information, but has also aggregated multi-angled social, cultural, and organisational views (e.g., web/tweets information from different countries and from companies with a variety of cultural backgrounds). Such social network information is available to all the actors within the network and financial Social Machines can use all information on the web to improve financial decision-making processes (Lau et al., 2012). Therefore, such Social Machines have enabled various actors, such as institutional and individual investment decision-makers, to acquire constant access to a wide range of information resources such as Twitter, which has improved the aggregate information environment for traders (Xu and Zhang, 2013).

For financial markets, there are two primary methodologies for using Social Media to access market prices. The first looks at the evaluation of volumes; for example, analysing the volume of search engine queries and Wikipedia views and edits. The second type is to extract content about them from social media messages through the wisdom of the crowd. For example, Zhang et al. 
(2011) aimed to anticipate markets ahead of time by looking at internet messages from a large group of individuals in advance of price changes. They found that - when applied to the analysis - a group tended to be a greater predictor (on average) than an individual. Therefore, by classifying text-strings into emotional scales, arguably this enables the generation of a richer amount of information to predict markets. Consequently, financial institutions have increasingly adopted this approach. Appendix 2 shows a detailed summary of research findings using social media information for financial markets. Another example is that an analysis of tweets, and other comparable data sources such as Google trends, and Yahoo search engine data (Moat et al., 2013) can shed light on the informational inefficiencies that exist within financial markets (Grossman and Stiglitz, 1980). Yang et al. (2015) identify a financial community and the critical nodes (e.g., key actors within the finance network) that are influential in propagating information to others. They find that these critical actors are significantly predictive of market return and predicate market volatility, which also confirms the view of increasing dominance of key actors through the financialisation and ultra-capital processes (Cloke, 2013). For example, Bollen et al. (2011) found they could use sentiment in Twitter to predict market closing prices (up or down) with an accuracy of $87.6 \%$. With such a high level of accuracy, this shows that technical analysis using social media information will allow capable actors (e.g., traders) to spot sophisticated market information effectively.

Consequently, such social media has revolutionised how financial institutions operate (Aral et al., 2013) and is a rich source of information that many actors within the financial network (e.g., traders, banks, hedge funds, government and the public) are increasingly using as a source of competitive advantage as well as an important pathway to influence relevant actors. Actually, it has been widely acknowledged that the impact of social network reaches far beyond just financial markets. It has profoundly transformed our society, culture, politics and business, and people's socialisation. These profound impacts will also accelerate the financialisation process as well as market price fabrication. However, as more individuals and organisations become reliant on such social networks and thus financial Social Machines, it can also create volatility. For example, on April 23rd, 2014 at 13.07, a fake tweet on Twitter was sent from the Associated Press about an explosion at the White House injuring the president. Within just a few minutes a sudden plunge of the price of Standard \& Poor's 500 index fell by $1 \%$, where $£ 90$ billion was effectively wiped off the US stock market (see Figure 4).

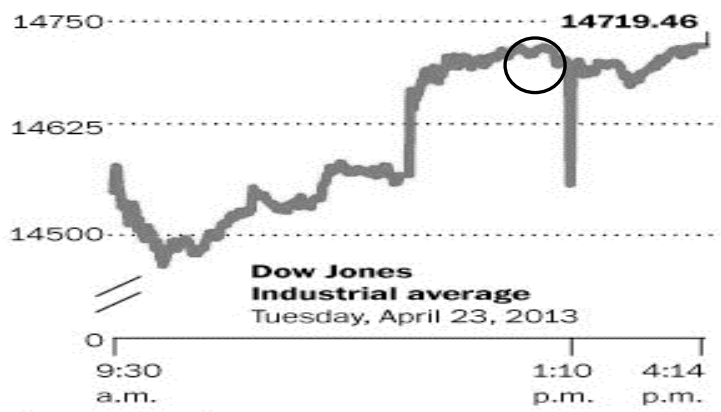

Fig 4.

Illustration of S\&P after a brief sell-off that occurred after the Associated Press' Twitter account was hacked and a fake tweet sent reporting explosions at the White House.

Therefore, as Social Machines affect market price fabrication, new tools and techniques need to take into account such negative effects of social network influence not only on the financial market but also on society as a whole. It is not the typical quantitative data traditionally used in the financial industry; so not only does this require new techniques to improve the conversion of text-string data into sentiment results, but also new methodologies that can undertake insightful analysis of these sentiment data. One example is Signal Diffusion Mapping (Gaskell et al., 2014), a new TimeSeries analysis methodology for forecasting financial market movement. The purpose of the technology is to measure information and price at time-varying lag-lengths between two time series. For example, arguably, insider trading affects the informationto-price time lag. Other significant factors that distort this relationship are variables such as news, speculative forces and bandwagon affects. According to Cheung et al. (2004), these are the main drivers of price within a day, and fundamentals that typical financial theory assumes are key drivers of price are only relevant when trying to determine the returns over the long term. According to Soros (2008), some reflexivity relationships are sustained for extended periods, while others fizzle out over shorter periods. Therefore, when trying to identify the relationship between these variables, Gaskell and colleagues (2014) describe it as like trying to eat soup with a fork - quite simply the wrong tools for the job. Therefore, Signal Diffusion Mapping demonstrates the ability, and need, to handle lags of such variables. The authors found that some events had a quicker price response time than others; similarly, sometimes the price moved before the news had even come out. This result is interesting in the context of financialisation, as it demonstrates that social networks become part of the overall complex financial network and allow various actors to exchange views of both historical financial markets' information and future trends, which has aggregated social, cultural and organisational aspects, thus showing good predictability. On the other hand, financial markets will also reshape actors' reactions; they may have a profound influence on how they behave in their business activities and thus reform the price fabrication. Therefore, such interactions of humans and Social Machines within financial markets have indeed demonstrated the social aspects of the financialisation process, highlighting the need for a broader financialisation view for solving emerging finance research challenges.

In summary, social network technologies allows people to create, share and exchange information. Social network techniques such as sentiment analysis - then allow the sharing of moods, perceptions and opinions of much of the world's population in an ag- 
gregated and real-time manner (Zhuleduv, 2014). Such Social Machines have profoundly influenced our society, business, interactions among people/organisations, and global financialisation processes. Subsequently they are increasingly adopted by financial institutions, such as automated trading, as the forming of financial Social Machines for forecasting and identifying investment opportunities within financial markets is an important new infrastructure of this complex financial information network.

\section{Case Study 3: Speculative Trading and INCREASED LEVERAGE WITH DIGITAL DIVIDE: MOBILE INTERNET AND INDIVIDUAL TRADING BEHAVIOUR}

Mobile Information Technology (MIT) improves and expands our ability to communicate and share information of individuals. According to Cisco (2015), there were 7.4 billion connections generated via smart mobile phones by the end of 2014 and it is expected that this will reach 12 billion in 2019. The mobile internet and its users also form the complex information and ubiquitous decisionsupport network for financial sectors; and have important roles to play in financialisation. Society tends to welcome such techno-cultural changes, which result in major social and cultural transformations (Cooper, 2002) and subsequent changes in individuals' decision-making processes.

Molloy and Schwenk (1995) find that MIT improves decision-making processes and permits individuals and organisations to access more accurate and current data. Such advantages have boosted the development of the mobile internet and particularly Smart Phones, as these provide access to information, enabling interaction at almost any time and anywhere ( Sraeel, 2006; KoenigLewis et al., 2010; Kourouthanassis and Giaglis, 2012; Buijink,

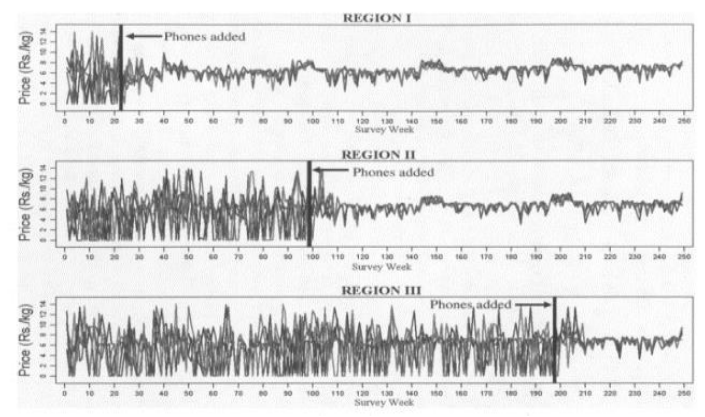

Fig5.

From the Kerala Fisherman's Survey conducted by Jensen (2007). The price series represent the average 7.30-8.00 am prices (in 2001

Visser and Marshall, 2013; Constantiou, 2014). Jensen (2007) explicates how the introduction of mobile phones improves information flow and hence efficiency. This is illustrated in Figure 5, which shows how pricing in the market for sardines in India changed when mobile phones were introduced. However, measuring the impact of mobile technology on financial markets involves factors associated with individual preferences, culture, and social context, among others( Venkatesh et al., 2003; Nakasumi, 2012; Venkatesh et al., 2012; Constantiou et al., 2014). Yamaguchi (2006) found that Smart Phones empower trading and facilitate more frequent trading. Xu et al. (2011) suggest that the main motivation for using Smart Phones is information seeking. Furthermore, they discovered that financial traders tend to use Smart Phones for gathering information and for interacting, particularly to buy or sell financial instruments. With such fast technology evolution, though, speculative financial trading instruments and behaviour may arise as well. For example, spread trading is one such financial instrument that allows individuals to speculate on the movement of an underlying security (e.g., Indices, FX, Shares, and Commodities). There is no ownership of the underlying security in place, and because it is classed as betting, it is not subject to capital gains tax. This is important, because investors in these markets have no reason to close trades or to cease trading for tax purposes (as is the case for investors in regular financial markets) and such speculative trading involves more and more individuals, who can simply use their mobile to trade on the direction of the market. In the UK, there are about half a million financial spread traders operating and this number is expected to reach one million by 2017 (Pryor, 2011). Brady and Ramyar (2006) indicate that, of the $£ 1.2$ trillion traded annually on the London Stock Exchange alone, $40 \%$ is equity derivative-related and $25 \%$ of this relates to spread trading ( $£ 120$ billion). Therefore, as the smart mobile technology and ubiquitous mobile internet become readily available to individuals an increasing trend of speculative behaviour among high-leverage trading-associated individuals has emerged. Although such market speculation may improve market efficiency and liquidity, from a financialisation perspective, Lagoarde-Segot (2016) postulates that such an increasing trend of leverage speculation has highlighted a number of social welfare and ethics concerns. These include (i) with no underlining stock ownership, what is the actual shareholder's value for such trading and how can shareholders' value even be maximised? and (ii) how can such speculative trading and high leverage be regulated to improve the financial system's and society's sustainability?

In addition, since such high leverage speculative trading has a low entry bar to any individual through smart mobile technology, and because individuals can trade at any time and anywhere, we raise the following question related to financialisation: what is the role and impact of mobile technology on social/income inequality and social divide in the digital age? Moreno Paredes et al. (2014) examined 4.5 million trades of over 5000 investors in the UK spread trading markets for 10 years. The results show that those who use Smart Phones at some time tend to 
achieve higher Sharp Ratios (e.g., risk-adjusted returns). Significantly, those who at some point have used Smart Phones for trading achieve improved performance (in terms of returns) and risk control (higher Sharp Ratios) when they use Smart Phones compared to when they use traditional trading channels. This result implies that the smart mobile technology may improve information flow through such mobile information networks by enabling traders to make better financial decisions (e.g., improve risk control). Similar results have been obtained in a range of studies examining investors in more traditional financial markets (e.g., Feng and Seasholes, 2005; Dhar and Zhu, 2006; Greenwood and Nagel, 2009; Linnainmaa, 2011). Barber and Odean (2000) suggest that there are many similarities in the behaviour of traders and investors in wider financial markets, suggesting that the relation to the effect of the Smart Phone on trading decisions has extensive applications. However, on the other hand, this result also suggests that those who choose to use Smart Phones possess superior decision skills on financial behaviour and performance (i.e. demographic characteristics, experience, and risk appetite). This superiority of the smart mobile users demonstrates greater gaps in the digital divide effect-an economic and social inequality with regard to access to and use of information technologies (Forman, 2005).

In summary, the rapid development of mobile technology with billions of users allows us to envisage financial markets as financial Social Machines with mobility. We believe though that the role of technology is more important than ever as the population now comprises human and machine traders - i.e. a Social Machine. As Hendler and Berners-Lee (2010, p.160) describe Social Machines, the same can be said of the financial markets:

"Our focus is not primarily in terms of the cyber-infrastructure of high-speed supercomputers and their networked interconnections, but the even more powerful human interactions enabled by these underlying systems". Mobile technology has changed the ways in which human investors trade in the market and by implication the underlying financial market interactions. As the technology splits people into groups with various levels of financial decision-making skills, those who employ technology to access complex information and use it to improve their financial decisions (Hui and Png, 2015) may gain additional advantages and thus widen the income inequity. Consequently, the mobile technology and increased speculative (high advantage) trading may further widen the social/digital divide and have profound implications for the global financialisation process - a process that may take income inequalities to unsustainable levels (Lin and Tomaskovic-Devey, 2013).

\section{DISCUSSION}

Information technology has rapidly evolved beyond just the computational aspects. The internet technology in particular involves interactions between human beings and computers through complex information networks, as Social Machines.
Such Social Machines are now embedded with social practices and the cultural, temporal and contextual aspects of information sharing (Akhlaghpour et al., 2013), and this has a profound impact on society and business activities and specifically on financial innovations. MacKenzie et al. (2012) suggest that by exploring how financial innovations create opportunities and threats for investors and transform financial market reactions, we can open up new perspectives on financial innovations. Similarly, this will offer social groups a specific language with which to articulate their concerns about justice in the context of financial markets. Therefore, analysis of such Social Machines provides a framework within which we are better able to understand how social practices and financialisation processes are constantly changing (Smart et al., 2014) toward further financial integration with evolved financial market efficiency (Lo, 2012). Ghose and Yao (2011) explain that internet-based markets should reduce transaction costs and create better financial integration. Indeed the Law of One Price where the price for a certain stock is the same across all markets becomes increasingly questionable as certain stocks exist in multiple markets and in different forms: Alsayed and McGroarty (2012) show that mispricing of American depository receipts incentivises arbitrageurs to trade on discrepancies, which leads to market integrations. Moreover, the speed of such a process has also been particularly accelerated by high frequency trading, but the ever-growing automated algorithm trading produces many misalignments between "coding and code of conducts" (Lenglet, 2011). Consequently, financialisation and information system research needs to examine the unintended and unexpected outcomes that are beyond that originally intended. The flash crash example raised regulation, political and social issue in regards to the morality and fairness of algorithmic trading.

In addition, the rapid expansion of social networks has profound implications for the financial system and our society. Such social network-based machines include various actors, such as institutional investors, public media groups, governments, financial professionals, individuals with various social backgrounds, and business executives (Boussard, 2016) who can exchange their opinions at any time and anywhere on any topic. However, these Social Machines are embedded in interpersonal networks, geographical territories, political views and cultural forms (Hertz, 1998; Muniesa, 2014). Taken together, high-speed trading, international financial integration and the rise of speculative behaviour have further complicated the global financialisation process. Sometimes these Social Machines may have a significant negative impact on the financial system stability, and may result in increased volumes of speculation behaviour. Future policy needs to be flexible enough so that it does not hinder innovation, but at the same time regulated sufficiently so that we can stabilise potential market vulnerabilities that arise through the continual improvement and adoption of these technologies. Regulation must be in place to prevent crashes and enforce a fair global financial system. 
Furthermore, as human traders become reliant on ubiquitous available networks, smart mobiles and social networkbased information, this may also lead to financial inequality or even social instability and increased speculation. Such mobile technology may increase the dominance of noise traders who only have 'bounded rationality'. Some behaviour finance literature (e.g., Shiller, 2002) contends that these traders account for the extreme volatility observed in financial markets. The irrationality of these traders in speculative markets increases the risk and the cost of speculation, potentially destabilising the financial systems within an increasingly fragmented market. Further research on Social Machines and financialisation may help frame how the financial systems connect multiple markets and individuals (Smart et al., 2014, points 2 and 3). Empowered with the goal of driving out mispricing, the Social Machine identifies an individual's speculation and irrationality that may lead to market instability. Attention then turns towards understanding the makeup of financial markets as Social Machines so that they can be regulated properly. The proposed new regulatory directives (MiFID II) will be published and enshrined in national law by January 2017. The proposed new regulatory effects will increase realtime reporting but, in many cases, implementing such systems will be costly, difficult to put in place, and take years for many companies to achieve, suggesting that, as yet, "we are not ready" (Loi et al., 2015).

Another consequence of the emergence of Social Machines is the fragmentation of the trading floor. As Moreno Paredes et al. (2014) argue, smart mobile technology may on the one hand enhance financial decision-making, but on the other hand may worsen the social divide due to the development of digital technology. Technologically deprived people may not be able to adopt the constant evolving innovative technology, which may have a negative impact on their income. Clearly, such a trend will widen the income inequality gap; such rising inequality has inevitable profound distributional and welfare consequences for different social groups and compounds the current imbalance in the distribution of technological power among different social groups.

Overall, social, economic and financial factors have to be embedded in environmental and social welfare actions to address the challenges we face, rather than the opposite (Lagoarde-Segot and Paranque, 2016). This assertion is also supported by the theory of ultra-capital (Cloke, 2013), a social construct and framework of how interdisciplinary dialogue can improve our understanding of the relationship between asset trading in the globalised digital market, and the broader socio-political context. Moreover, regulators themselves face considerable difficulty in implementing policy as Social Machine technology advances drive competition and market efficiency is adapting over time to the evolution of Social Machines. Important questions arise as to whether finance technology facilitates or impedes regulation, as policy must be in place to protect firms and consumers from financial misconduct. Such research questions as illustrated by Clemons et al. (2013) will support a better understanding of the complex nature of innovative information technology in financial systems and inform government accordingly. This will also help inform the regulatory enforcement mechanisms, which becomes a complicated multi-faceted initiative in that enforcement is not guaranteed by regulatory mandate. The regulatory is increasingly difficult with businesses operating in multi-jurisdictional areas and, despite rules being put in place, individuals are able to bypass such systems (Gozman and Currie, 2014). One potential way to achieve enforcement is through whistleblowing whereby financial institutions or individual traders that produce evidence of malpractice are richly rewarded. However, even though such systems that rely on social ties are dependent on the technology used to trade and monitor behaviour, the importance of effective systems for whistleblowing among financial traders that enforces anonymity and trust is paramount (Lowry et al., 2013). Therefore, regulatory compliance is not a simple technology fix; rather it is dependent on a multitude of social, legal and operational factors. Social Machines once again help identify that these regulatory processes are not guaranteed but must be enacted by processes.

\section{CONCLUDING REMARKS}

This paper highlighted the emerging phenomenon of financial Social Machines with particular emphasis on three sample disruptive technologies - automated/high frequency trading, social network analytics and smart mobile technology. We addressed the research gap of emerging Social Machine and financialisation through critical reflective analysis undertaken in three distinct case studies. We explored the ecology of transaction speed on automated trading; financial information extraction using social media technologies; and information diffusion and trading decision-making linked to the use of mobile technology. We analysed how financial Social Machines transform various aspects of financial market activity, such as increased financial integration, transaction velocity, complex information network and speculative behaviour. We also discussed their subsequent impact on society, such as social divisions and income inequality, which may raise societal concerns and threaten sustainable stability on a global scale.

Our findings demonstrate that these technologies enable the formation of financial Social Machines, which integrate the innovative high-speed network, social media information, and trading decisions of individuals to provide more accurate price predictions leading to improved financial market integration. However, the race for speed, automation and information extraction can also have negative consequences for financial systems where, in some circumstances, these may reinforce and magnify underlying flaws, such as misinformation on social networks or volatility from automated trading caused by endogenous effects like herding instead of responding impartially and precise re- 
sponses to genuinely new information. The rapid rise in transaction velocity presents an emerging challenge, as future trading regulations will need to strike a balance between liquidity and stability (Lagorade-Segot, 2015). There is also a need to consider the broad range of financial sectors in the context of an inevitable globalised digitisation. Financial sectors in general are deeply embedded in society globally and so this digitisation has wide socio-political ramifications as well as socio-political constraints.

Moreover, human traders have become reliant on ubiquitously available mobile internet connectivity. However, such mobile technology may actually increase the proportion of noise trading. Evidence shows that irrational choices of mobile noise traders in spread-betting markets resulted in increased risk and higher costs. This - together with the increasing fragmentation of markets - could potentially destabilise the financial systems as a whole because increased speculative behaviour will lead to greater income inequity between the technologically advantaged and technologically disadvantaged individuals. This also raises moral questions regarding the alignment of societal expectations with business ethics. Consequently, the future research agenda on financialisation should be embedded in environmental and social welfare to address such challenges. Policy-makers need to keep up with the rate of technological change as we move towards a symbiotic human-machine financial system. Their policies need to be flexible enough so that they do not hinder innovation, but they must also ensure that the necessary safeguards are in place, e.g., to prohibit machines from operating ungoverned. Policymakers must also be aware of potential new problems that could arise through technological innovation. They need to anticipate emergent risks from the integration and advancement of these technologies and plan for their arrival.

\section{REFERENCES}

- Aalbers, M. B. (2015). Corporate financialization. In N. Castree (Eds.), The international encyclopedia of geography: People, the earth, environment, and technology. Oxford:Wiley.

- $\quad$ Akhlaghpour, S., Wu, J., Lapointe, L., and Pinsonneault, A. (2013). "The ongoing quest for the IT artifact: Looking back, moving forward", Journal of Information Technology (28:2), pp. 150-166.

- $\quad$ Alsayed, H., and McGroarty, F. (2012). “Arbitrage and the Law of One Price in the market for American depository receipts", Journal of International Financial Markets, Institutions and Money (22:5), pp. 1258-1276.

- Aral, S., Dellarocas, C., and Godes, D. (2013). "Business Transformation: A Framework for Research Social Media and Business Transformation : A Framework for Research," Information Systems Research (24:1), pp. 3-13.

- Arndt, H. (2006). "Enhancing system thinking in education using system dynamics". Simulation, 82(11), 795-
806.Bannister, F., and Remenyi, D. (2000). “Acts of faith: Instinct, value and IT investment decisions,"Journal of Information Technology (15:3), pp. 231-241.

- $\quad$ Barber, B.M. and Odean, T. (2000), "Trading is hazardous to your wealth: The common stock investment performance of individual investors", The Journal of Finance, Vol. 55, No. 2, pp. 773-806.

- $\quad$ Barber, B.M. and Odean, T. (2001), 'Boys will be boys: Gender, overconfidence, and common stock investment', The Quarterly Journal of Economics, Vol. 116, No. 1, pp. 261-292.

- $\quad$ Berners-Lee, T., and Fischetti, M. (1999). "Weaving the Web: The Original Design and Ultimate Destiny of the World Wide Web”, New York: Harper Collins.

- $\quad$ Bollen, J., Mao, H., and Zeng, X. 2011. "Twitter mood predicts the stock market", Journal of Computational Science (2:1), pp. 1-8.

- Boussard, V. (2016). "Finance at work". London: Routledge.

- $\quad$ Brady, C., \& Ramyar, R. (2006). "White Paper on spread betting. London”. Cass Business School.

- $\quad$ Brandt, T., and Neumann, D. (2015). "Chasing Lemmings: Modeling IT-Induced Misperceptions About the Strategic Situation as a Reason for Flash Crashes," Journal of Management Information Systems (31:4), pp. 88-108.

- $\quad$ Brogaard, J. a. (2010). "High Frequency Trading and Its Impact on Market Quality”, No. 66, Northwestern University Kellogg School of Management Working Paper.

- $\quad$ Brogaard, J., Hendershott, T., and Riordan, R. 2014. "High-frequency trading and price discovery", Review of Financial Studies (27:8), pp. 2267-2306.

- Buijink, A., Visser, B.J. and Marshall, L. (2013), "Medical apps for smartphones: Lack of evidence undermines quality and safety", Evid Based Med, Vol. 18, No. 3, pp. 90-2.

- Cameron, T. C., O'Sullivan, D., Reynolds, A., Piertney, S. B., and Benton, T. G. (2013). Eco-evolutionary dynamics in response to selection on life-history. Ecology letters.

- Cavaye, A. (1996). “Case Study Research: a multi-faceteted research approach for IS". Information Systems Journal, (6), pp. 227-242.

- CFTC. (2010). "Findings regarding the market events of May 6, 2010," Commodities and Futures Trading Commission (CFTC), 2010. Findings Regarding the Market Events of May 5, 2010. September 30, Securities and Exchange Commission. Joint publisher,Washington, DC (Available at www.cftc.gov/ucm/groups/public/@otherif/documents/.

- Chaboud, A. P., Chiquoine, B., Hjalmarsson, E. and Vega, C. (2014), "Rise of the Machines: Algorithmic Trading in the Foreign Exchange Market", The Journal 
of Finance, 69(5), pp. 2045-2084.

- $\quad$ Chang, R. M., Kauffman, R. J., and Kwon, Y. (2014). "Understanding the paradigm shift to computational social science in the presence of big data", Decision Support Systems (63), pp. 67-80.

- $\quad$ Chen, H., De, P., Hu, Y. Y., and Hwang, B.-H. (2014). "Wisdom of Crowds: The Value of Stock Opinions Transmitted Through Social Media," Review of Financial Studies (27:5), pp. 1367-1403.

- $\quad$ Cheung, Y.K., Chinn, M.D., and Marsh, I.W. (2004). "How do UK-based foreign exchange dealers think their market operates?", International Journal of Finance and Economics, (9), pp. 289-306

- Clemons, E.K. et al. (2013). Impactful Research on Transformational Information Technology: An Opportunity to Inform New Audiences. MIS Quarterly, 37(2), pp.371-382.

- Cloke, J. (2010). Capital is dead: Long live ultra-capital. In T. Lagoarde-Segot (Ed.). After the crisis: Rethinking finance (pp. 1-16). Nova Science.

- Cloke, J. (2013). “Actor-network capitalism and the evolution of ultra-capital. Working paper”. University of Helsinki.

- Constantiou, I. D., and Kallinikos, J. (2015). "New games, new rules: Big data and the changing context of strategy", Journal of Information Technology (30:1), pp. 44-57.

- $\quad$ Constantiou, I.D., Lehrer, C. \& Hess, T., (2014). "Changing information retrieval behaviours : an empirical investigation of users' cognitive processes in the choice of location-based services", European Journal of Information Systems, 23(5), pp.513-528.

- Cooper, S. (2002). "Techno-culture and critical theory". In the service of the machine? Routledge, London and New York.

- $\quad$ Darke, P., Shanks, G., and Broadbentm M. (1998). "Successfully completing case study research: combining rigour, relevance and pragmatism", Information Systems Journalm (8), pp. 273-289.

- Denzin, NK. (1978). “Sociological Methods”, New York: McGraw-Hill.

- $\quad$ Dhar, R. and Zhu, N. (2006), "Up close and personal: Investor sophistication and the disposition effect", Management Science, Vol. 52, No. 5, pp. 726-740.

- Drnevich, P.L. \& Croson, D.C. (2013). "Information technology and business-level strategy: toward an integrated theoretical perspective". MIS Quarterly, 37(2), pp.483-509.

- $\quad$ Ekbia, H., Mattioli, M., Kouper, I., Arave, G., Ghazinejad, A., Bowman, T., Suri, V. R., Tsou, A., Weingart, S., and Sugimoto, C. R. 2015. "Big Data, Bigger Dilemmas: A critical review", Journal of the Association for Information Science and Technology (66:8), pp. 1523-1545.

- Farmer, J. D. 'Toward Agent-Based Models for
Investment.' In Developments in Quantitative Investment Models, AIMR (2001).

- Feenberg, A. (2005). "Critical Theory of Technology: An Overview”, TAILORING BIOTECHNOLOGIES, Vol. 1, Issue 1, pp: 47-64.

- $\quad$ Feng, L. and Seasholes, M.S. (2005), "Do investor sophistication and trading experience eliminate behavioral biases in financial markets?", Review of Finance, Vol. 9, No. 3, pp. 305-351

- Forman, C. (2005), "The corporate digital divide: Determinants of internet adoption". Management Science, Vol. 51, No. 4, pp. 641-654.

- Foucault, Thierry, Johan Hombert, and Ioanid Roşu. "News trading and speed", The Journal of Finance (2015).

- $\quad$ Gaskell, P., McGroarty, F., and Tiropanis, T. (2015). "Signal Diffusion Mapping: Optimal Forecasting With Time-Varying Lags", Journal of Forecasting (35:1), pp. 70-85.

- $\quad$ Ghose, A., and Yao, Y. 2011. "Using transaction prices to re-examine price dispersion in electronic markets," Information Systems Research (22:2), pp. 269-288.

- Gozman, D., and Currie, W. (2014). "The role of investment management systems in regulatory compliance: a Post-financial crisis study of displacement mechanisms", Journal of Information Technology (29:1), pp. 44-58.

- Gozman, D., and Currie, W. (2014). "The role of investment management systems in regulatory compliance: a Post-financial crisis study of displacement mechanisms," Journal of Information Technology (29:1), pp. 44-58.

- Granados, N., Gupta, A., and Kauffmann, R. (2006). "The Impact of IT on Market Information and Transparency: A Unified Theoretical Framework", Journal of the Association for Information Systems, (7:3), pp. 148-178.

- $\quad$ Greenwood, R. and Nagel, S. (2009), "Inexperienced investors and bubbles", Journal of Financial Economics, Vol. 93, No. 2, pp. 239-258.

- Grossman, S. and Stiglitz, J. (1980). "On the Impossibility of Informationally Efficient Markets" American Economic Review, (70), pp. 393-408

- Hasbrouck, J., and Saar, G. 2013. "Low-latency trading”, Journal of Financial Markets (16:4), Elsevier, pp. 646-679.

- Hendershott, T., and Moulton, P. C. (2011). "Automation, speed, and stock market quality: The NYSE's Hybrid”, Journal of Financial Markets (14:4), Elsevier, pp. 568-604.

- Hendershott, T., Jones, C. M., \& Menkveld, A. J. 2011. "Does algorithmic trading improve liquidity?" The Journal of Finance, 66(1), 1-33.

- Hendler, J., and Berners-Lee, T. 2010. "From the Semantic Web to Social Machines: A research challenge 
for AI on the World Wide Web," Artificial Intelligence (174:2), pp. 156-161.

- Hertz, E. (1998). The trading crowd: An ethnography of the shanghai stock market. Cambridge: Cambridge University Press.

- Hui, K.-L. and Png, I. (2015), "Research note-migration of service to the internet: Evidence from a federal natural experiment". Information Systems Research, Vol. 26, No. 3, pp. 606-618.

- Jain, P. 2004. "Financial Market Design and Equity Premium : Electronic versus Floor Trading”, The Journal of Finance, pp. 2955-2985.

- Jensen, R. T. (2007). "The Digital Provide: Information (Technology), Market Performance, and Welfare in the South Indian Fisheries Sector". Quarterly Journal of Economics, 122(3), 879-924.

- Johnson, N., Zhao, G., Hunsader, E., Qi, H., Johnson, N., Meng, J., and Tivnan, B. 2013. "Abrupt rise of new machine ecology beyond human response time", Scientific reports (3), p. 2627.

- Karppi, T., and Crawford, K. (2016). "Social Media, Financial Algorithms and the Hack Crash" Theory, Culture \& Society (33:1), pp. 73-92.

- Kirilenko, a, Kyle, A., and Samadi, M. (2010). “The flash crash: The impact of high frequency trading on an electronic market". (Available at SSRN 1686004)

- Koenig-Lewis, N., Palmer, A. and Moll, A. (2010), "Predicting young consumers' take up of mobile banking services", International journal of bank marketing, Vol. 28, No. 5, pp. 410-432.

- Kourouthanassis, P.E. and Giaglis, G.M. (2012), "Introduction to the special issue mobile commerce: The past, present, and future of mobile commerce research", International Journal of Electronic Commerce, Vol. 16, No. 4, pp. 5-18.

- Lagoarde-Segot, T. (2015). "Diversifying finance research: From financialization to sustainability". International Review of Finance Analysis, 39, 1-6.

- Lagoarde-Segot, T., \& Paranque, B. (2016). "Sustainability and the reconstruction of academic finance". Research in International Business and Finance

- Lagoarde-Segot, T., 2016. "Financialization: towards a new research agenda". International Review of Financial Analysis, forthcoming.

- $\quad$ Lau, R. Y. K., Liao, S. S. Y., Wong, K. F., and Chiu, D. K. W. (2012). "Web 2.0 Environmental scanning and adaptive decision support for business mergers and acquisitions," MIS Quarterly (36:4), pp. 1239-1268.

- Leinweber, D., and Sisk, J. (2011). "Relating news analytics to stock returns". In The Handbook of News Analytics in Finance. New York: John Wiley \& Sons.

- Lenglet, M. (2011). "Conflicting codes and coding: how algorithmic trasing is reshaping financial regulation". Theory, Culture and Society, 28(6): 44-66.
- $\quad$ Lin, K., \& Tomaskovic-Devey, T. (2013). "Financialization and U.S. income inequality, 1970-2008". American Journal of Sociology, 118, 1284-1329.

- Linnainmaa, J.T. (2011), "Why do (some) households trade so much?", Review of Financial Studies, Vol. 24, No. 5, pp. 1630-1666.

- Lo, A. (2012). "Adaptive Markets and the New World Order", Financial Analysts Journal (68:2), pp. 18-29.

- Lo, A., (2005). "Reconciling Efficient Markets with Behavioral Finance: The Adaptive Markets Hypothesis". The Journal of Investment Consulting, 7(2), pp.21-44.

- Lowry, P. B., Moody, G. D., Galletta, D. F., and Vance, A. (2013). "The Drivers in the Use of Online WhistleBlowing Reporting Systems", Journal of Management Information Systems (30:1), pp. 153-190.

- MacKenzie, D., Beunza, D., Milo, Y., Pardo-Guerra, J.P (2012). "Drilling through the Allegheny Mountains: liquidity, materiality and high-frequency trading". Journal of Cultural Economics, 5(3), 279-296.

- Molloy, S. and Schwenk, C.R. (1995), "The effects of information technology on strategic decision making", Journal of Management Studies, Vol. 32, No. 3, pp. 283-311.

- Moreno Paredes, JC., Sung, M., Ma, T and Johnson, J.E.V. (2014). "Investors on the move: discerning the influence of smart phones on investors' decision making". 14th International Conference of Management and Behavioural Sciences, Toronto, CA, 06 - 07 Dec 2014.

- Muniesa, F. (2014). The provoked economy: Economic reality and the performative turn. London: Routledge.

- Nakasumi, M. (2012), "Decision making aid in mobile environment by behavioral characteristic", Proceedings of the 13th International Conference on Electronic Commerce, Liverpool, United Kingdom: ACM.

- Orlikowski, W.J., and Baroudi, J.J. (1991). "Studying Information Technology in Organizations: Research Approaches and Assumptions", Information Systems Research, 2(1), pp. 1-8.

- Paul Stoneman, (1995), "The Handbook of Economics of Innovation and Technological Change", Blackwell, Cambridge MA.

- Pryor, M. (2011). "The financial spread betting handbook: a guide to making money trading spread bets". Harriman House Limited.

- $\quad$ Riordan, R., Storkenmaier, A., Wagener, M., and Sarah Zhang, S. (2013). "Public information arrival: Price discovery and liquidity in electronic limit order markets", Journal of Banking and Finance (37:4), pp. 1148-1159.

- Ryan Riordan, Andreas Storkenmaier (2012), "Latency, liquidity and price discovery". Journal of Financial Markets, Volume 15, Issue 4, November 2012, Pages 416437.

- Schumaker, Robert P., and Hsinchun Chen. "Evaluating a news-aware quantitative trader: The effect of 
momentum and contrarian stock selection strategies", Journal of the American Society for Information Science and technology 59.2 (2008): 247-255.

- Shadbolt, N., Smith, D. A., Simperl, E., Kleek, M. Van, and Yang, Y. (2013). "Towards a classification framework for Social Machines", in Proceedings of the SOCM2013: The Theory and Practice of Social Machines, Rio de Janeiro, Brazil, 13-17 May 2013, pp. $1-7$.

- $\quad$ Sherstov, A.A., and Stone, P. (2010). "Three Automated Stock-Trading Agents: A Comparative Study". Available At: http://www.cs.utexas.edu/ ailab/pubs/AMEC04-plat.pdf [Accessed 07/03/2016]

- Shiller, R. J. (2002). "Bubbles, human judgment, and expert opinion". Financial Analysts Journal, 58(3) (May/June).

- Smart, P., Simperl, E., and Shadbolt, N. 2014. "A Taxonomic Framework for Social Machines," Social Collective Intelligece, pp. 51-85.

- SOCIAM. (2015). Available At: http://www.sociam.org/ [Accessed 05/03/2016]

- Soros, G. (2008). "The new paradigm for financial markets: The credit crisis of 2008 and what it means", New York: Public Affairs

- Sprenger, T., Sandner, P., Tumasjan, A., and Welpe, I. (2014). "News or Noise? Using Twitter to Identify and Understand Company-specific News Flow", Journal of Business Finance \& Accounting (41:7-8), pp. 791-830.

- Sprenger, T., Tumasjan, A., Sandner, P., and Welpe, I. (2014). "Tweets and Trades: the Information Content of Stock Microblogs," European Financial Management (20:5), pp. 926-957.

- Sraeel, H. (2006), "Hold the phones: Mobile commerce is here", Bank Technology News.

- Sterman, J. D. (2000). "Business dynamics: systems thinking and modeling for a complex world". (No. HD30. 2 S7835 2000).

- Stoll, H. R. 2006. "Electronic Trading in Stock Markets", Journal of Economic Perspectives (20:1), pp. 153-174.

- Tversky, A. (1974) "Judgement under uncertainty: Heuristics and biases", Science (185:4157), pp. 1124-1131.

- Tversky, A., and Kahneman, D. (1974). Judgment under uncertainty: Heuristics and biases. science, 185(4157), 1124-1131.

- Uhl, M. (2014). "Reuters Sentiment and Stock Returns," Journal of Behavioral Finance (15), pp. 287-298.

- Venkatesh, V., Morris, M.G., Davis, G.B. and Davis, F.D. (2003), "User acceptance of information technology: Toward a unified view", MIS quarterly, pp. 425-478.

- Venkatesh, V., Thong, J. and Xu, X. (2012), "Consumer acceptance and use of information technology: Extending the unified theory of acceptance and use of technology”, MIS quarterly, Vol. 36, No. 1, pp. 157178.

- Vuorenmaa, T.A. (2012). "The Good, the Bad, and the Ugly of Automated High-Frequency Trading”, Available At: http://www.smallake.kr/wp-content/uploads/h/11/The-Good-the-Bad-and-the-Ugly-of-Automated-High-Frequency-Trading.pdf [Accessed 06/03/2016]

- World Economic Forum (2015). "Outlook on the global agenda 2015". http://reports.weforum.org/outlookglobal-agenda-2015/top-10-trends-of-2015/1-deepeningincome-inequality/

- $\quad \mathrm{Xu}, \mathrm{Q}$., Erman, J., Gerber, A., Mao, Z., Pang, J. and Venkataraman, S. (Year), "Identifying diverse usage behaviors of smartphone apps," Proceedings of the 2011 ACM SIGCOMM conference on Internet measurement conference, 2011: ACM, pp. 329-344.

- Xu, S. \& Zhang, X. (Michael), 2013.“ Impact of Wikipedia on Market Information Environment: Evidence on Management Disclosure and Investor Reaction". MIS Quarterly, 37(4), pp. 1043-1068.

- Xu, S. \& Zhang, X. (Michael). (2013). "Impact of Wikipedia on Market Information Environment: Evidence on Management Disclosure and Investor Reaction”. MIS Quarterly, 37(4), pp. 1043-1068.

- Yamaguchi, T. (2006), "Understanding trading behavior in 401(k) trading plans",

- $\quad$ Yang, S. Y., Mo, S. Y. K., and Liu, A. 2015. "Twitter financial community sentiment and its predictive relationship to stock market movement", Quantitative Finance (15:10), pp. 1637-1656

- Yin, R. ( 2003). "Case Study Research Design and Methods", second and third edition Applied Social Research Methods Series, Volume 5, Sage Publications.

- Zhang, X. (Michael), and Zhang, L. (2015). "How Does the Internet Affect the Financial Market? An Equilibrium Model of Internet-Facilitated Feedback Trading” MIS Quarterly (39:1), pp. 17-38.

- Zhang, X. (Michael), and Zhang, L. 2015. "How Does the Internet Affect the Financial Market? An Equilibrium Model of Internet-Facilitated Feedback Trading", MIS Quarterly (39:1), pp. 17-38.

- Zhang, X., Fuehres, H., and Gloor, P. (2011). "Predicting Stock Market Indicators Through Twitter: I hope it is not as bad as I fear", Procedia - Social and Behavioral Sciences (26), pp. 55-62

- Zheledev, I., Smith, R., and Ase, T. (2014). "When Can Social Media Lead Financial Markets?" Sci. Rep (4: 4213)

- Zigrand, J-P., and Cliff, D. (2011). "Financial Stability and Computer Based Trading", Available At: http://papers.ssrn.com/sol3/papers.cfm?abstract id=1569067 [Accessed 07/03/2016]

- Van der Zwan, N (2014). "Making sense of financialization". Socio-Economic Review 12 (1): 99-129. 